\title{
Month of Birth, a Risk Factor for Violent Behaviour in Suicidal Patients Admitted in Emergency?
}

\author{
Lionel Cailhol · Raluca Moraru • Remy Barbe · Anne-Hélène Moncany • \\ Sophie Garcin · Coralie Lazignac · Cristian Damsa
}

Published online: 21 April 2009

(C) Springer Science+Business Media, LLC 2009

\begin{abstract}
Although there are numerous publications on the existing link between month of birth and suicide, only two studies focus on suicide attempts and auto-aggressive behavior. Research data suggest that month of birth is related to a variation of 5-HIAA in the cerebrospinal fluid, which correlates with violent behavior (VB). Therefore, the aim of this study is to search, for the first time, for a possible link between month of birth and the occurrence of VB in emergency, for patients admitted for a suicide attempt with medication. This is a 10 months prospective study among all the patients of the canton of Geneva, Switzerland, admitted in emergency for a suicide attempt with medication. During a 10 months study period we included 493 patients, of which 77 (15.62\%) presented VB. Higher incidence of VB was found in subjects where born at the end of winter and the beginning of spring, with a maximum for April and a minimum for December. In spite of a relatively small number of subjects, it seems promising to study the occurrence of VB as a function of month of birth in patients admitted in emergency for a suicide attempt.
\end{abstract}

Keywords Month of birth - Suicide attempt with medication · Violent behavior . Emergency

This paper was presented as a new research poster in the last APA Congress May 2007.

L. Cailhol · A.-H. Moncany

Service of psychiatry and medical psychology, Universitary Hospital of Purpan-Casselardit, 170, Avenue de Casselardit, 31059 Toulouse, Cedex, France

L. Cailhol · R. Moraru · R. Barbe · S. Garcin · C. Lazignac · C. Damsa

Cantonal Universitary Hospital Geneva, 24, rue Micheli-du-Crest, 1211 Geneva, Switzerland

C. Damsa $(\bowtie)$

Department of Psychiatry, Clinical Investigation Program, University of Colorado Health Sciences Center, 4455 East 12th Avenue, Denver, CO 80220, USA

e-mail: c.damsa@bluewin.ch 


\section{Introduction}

Certain pseudo-sciences of "astrologic inspiration" seemed to have monopolized the debate over the impact of date and place of birth on the individual development, throughout the intensive use of horoscope. Nevertheless, as early as 1938, medical doctors were already attracted by this subject [1]. Recently, several papers suggests that month of birth seems to be a risk factor for several diseases such as epilepsy [2], breast [3], and testicular [4] cancer, Crohn disease [5], certain cardio-vascular diseases [6], and even for lymphoblastic leukemia in childrens [7]. This epidemiologic data were assumed to be in relationship with potential environmental risk factors: intra-uterine, perinatal, and postnatal factors, such viral infections [8].

Several psychiatric studies mentioned a higher frequency of winter and spring birth date for patients with schizophrenia and of spring and summer birth date for patients with affective disorders [9, 10]. However, this data has not always been confirmed [11].

While Doblhammer and Vaupel [12] suggests the existence of a relation between the month of birth and longevity, Salib and Cortina-Borja [13] searched a link with suicide. In spite of several geographical differences, it seems that people born in spring have a higher risk of suicide [13, 14]. Some hypotheses have been advanced in order to explain the link between suicide and month of birth. A neuro-developmental hypothesis involves the sensitivity of the central nervous system of the uterine environment towards certain variations related to seasonal changes: maternal infections, diet, photoperiod, temperature. A neuro-biochemical hypothesis, involving the serotoninergic system is based on a lower level of the serotoninergic metabolite 5-HIAA in the cerebrospinal fluid of the patients with suicidal behavior [15] and on a lower level of 5-HIAA occurring in people born in spring [16].

In spite of the abundant research on the month of birth as a risk factor for suicide $[9,13]$, we found only two papers about month of birth and suicide attempts (SA) or self-mutilation [17-19]. While many data show a relation between suicide attempts, suicide, and serotoninergic pathways [20], studies of psychological autopsy of suicide suggest that violent suicide methods are associated with more aggressive and violent behavior (VB) during life [21]. Moreover, VB seems to be related to the 5-HIAA levels which vary also with the date of birth [16].

Integrating these literature data, it appears interesting to study for the first time the relationship existing between the month of birth of suicidal patients with or without violent behavior (Fig. 1). The identification of a stronger link with the date of birth for the subgroup of patients with VB and suicide attempt than for the patients without VB, might suggest the existence of a neurobiological feature, possibly related to the serotoninergic pathways.

\section{Method}

This study was conducted on patients admitted at the only center for psychiatric emergencies in the canton of Geneva (450,000 inhabitants), Switzerland, admitted for a suicide attempt by medication, during a 10 months period. The comprehensive screening of all suicide attempts, socio-demographic data and the presence of VB were gathered prospectively for a randomized study searching the efficacy of a specific crisis intervention in emergency. Data were anonymized and treated by an independent investigator, accordingly to the ethical norms present in Geneva. 


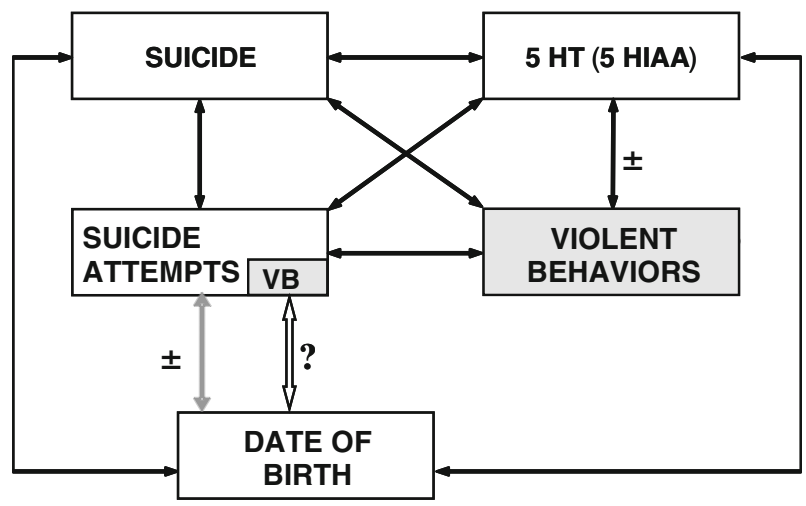

Fig. 1 Literature review and Study hypothesis. An extensive Medline review (1965-2007) illustrate that in spite of the abundant data concerning links between the month of birth, suicide, serotonin (and 5-HIAA), there are only two papers about the month of birth and suicide attempts $( \pm)$. Moreover, many data show links between suicide attempts, suicide, violent behaviors, and serotonin (5-HIAA). Integrating those data to some studies suggesting $( \pm)$ a link between violent behavior and 5-HIAA, it seems interesting to study for the first time the relationship (?) between the patients with suicidal attempts and violent behavior and their date of birth. The identification of a stronger link with the date of birth for the subgroup of patients with violent behaviors and suicide attempt, might suggest the existence of a specific neurobiological feature, possibly related to the serotoninergic pathways

During the screening period of 10 months 493 patients $(10.3 \%)$ committed suicide attempts by volunteer drug intoxication requiring a somatic surveillance.

The presence of VB was assessed by means of a questionnaire which describes the nature and the circumstances of the violent acts [22].

Data were analyzed with the SPSS 12.01 program and the $t$ square test with $2 * 2$ tables were used to compare each birth month with the others and also with the annual average. The $t$-student test was used to study the gender differences.

\section{Results}

VB was found in 77 subjects (15.62\%) from 493 patients admitted for suicidal attempt. Patients born in April had more VB (31.03\%) in comparison with those born in May (10.26\%; $\left.\chi^{2}=5.74 ; P=0.017\right)$, June $\left(7.14 \% ; \chi^{2}=6.04 ; P=0.014\right)$, July $(10.26 \%$; $\left.\chi^{2}=5.74 ; P=0.017\right)$, September $\left(13.73 \% ; \chi^{2}=4.60 ; P=0.032\right)$, October $(13.64$; $\left.\chi^{2}=4.21 ; P=0.040\right)$, November $\left(11.76 \% ; \chi^{2}=5.87 ; P=0.015\right)$ and December (2.94\%; $\left.\chi^{2}=10.32 ; P=0.001\right)$. Moreover, patients born in December had less VB than those born in January $\left(20.00 \% ; \chi^{2}=4.76 ; P=0.029\right)$, February $\left(20.00 \% ; \chi^{2}=4.90\right.$; $P=0.027)$, Mars (15.22\%; $\left.\chi^{2}=3.27 ; \quad P=0.007\right)$, April $\left(31.03 \% ; \quad \chi^{2}=10.32\right.$; $P=0.001)$ and August $\left(23.68 \% ; \chi^{2}=6.45 ; P=0.011\right)$. In comparison with the total number of VB divided by the total number of subjects, patients born in April have a higher number of VB, while those born in December present less VB (Fig. 2).

Even if no significant difference was found among the four seasons, patients born in January, February, March, and April had more VB (22.49\%) compared to those born in September, October, November, and December $(11.11 \%), \chi^{2}=8.14 ; P=0.004$.

No significant difference was found between men and women considering the possible influence of their month of birth for the violent behavior. 


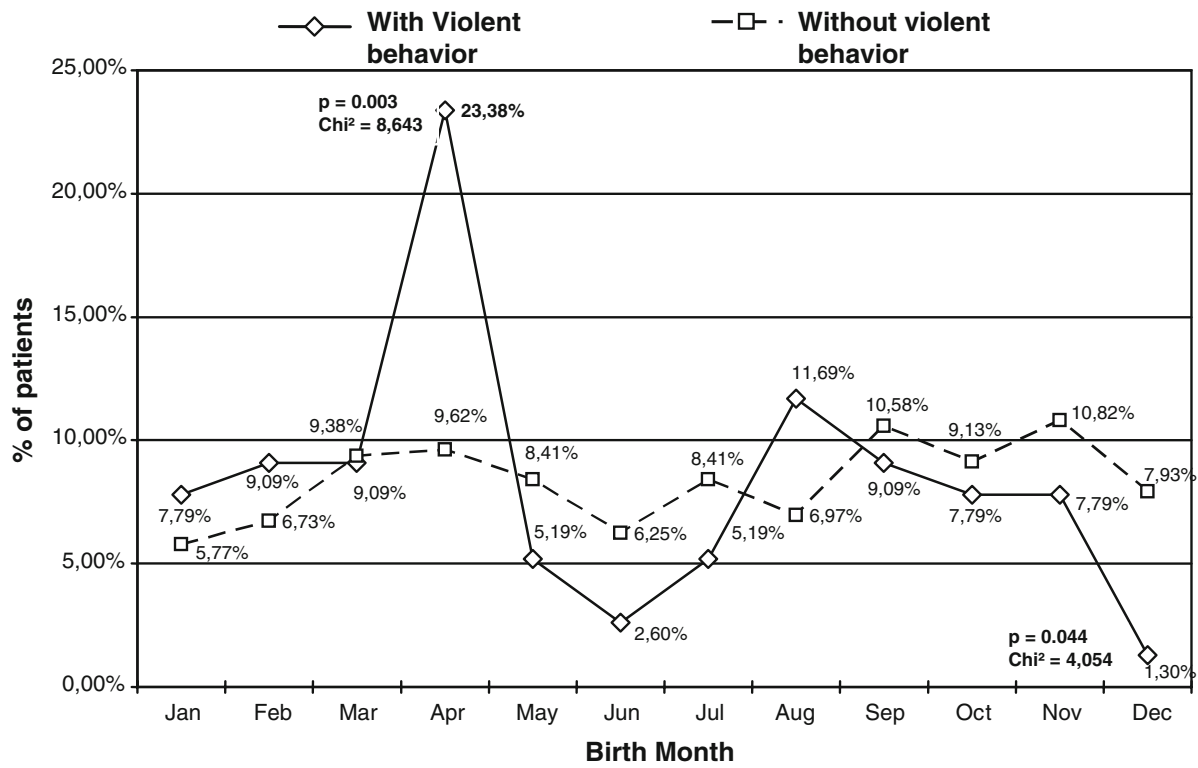

Fig. 2 Month of birth of patients with and without violent behaviour, admitted in emergency after a suicide attempt

\section{Discussion}

The interest of this study reside is the lack of balance in the literature between many papers studying the relation month of birth and suicide [9, 13], compared to only three studies about month of birth and suicide attempt or self-mutilative behavior [17-19]. Moreover, this is the first study which suggests a bigger influence of month of birth as a risk factor in suicidal patients with violent behaviour. Thus, taking into account the presence of a violent behaviour in patients with suicidal attempts could be an interesting way for future studies about the influence of the birth month.

Those data are in accordance with a higher frequency of suicide attempts for patients born in spring [17, 18], but also with data suggesting more dead following a suicide attempt for people born in spring [13, 14]. Interestingly, these results seems also in accord with lower values of 5-HIAA found in cerebrospinal fluid of patients born in spring [16, 23]. Nevertheless, our data are not concordant with a study which found that adolescents born during autumn had more chance to have a self-mutilative behavior [19]. Beside of methodological limitation of this study (small sample), those differences could be related to the differences of seasons (lightening, nutritional factors, etc.) between Finland and Switzerland, but also to the differences between violent behavior in adults versus selfmutilative behavior in adolescents.

\section{Conclusion}

In spite of a small number of subjects (493), this study suggests that VB could be an interesting factor for the study of the relation between suicidal behavior and the birth 
month. Further studies should search the existence of a subgroup of patients born in spring having a higher risk of VB and some specific serotoninergic patterns (lower 5-HIAA in the cerebrospinal fluid).

Acknowledgments We thank Dr. Damsa Traian for his commentaries on the manuscript.

\section{References}

1. Huntington E: Season of birth: Its relation to human abilities. New York, Wiley, 1938

2. Torrey EF, Miller J, Rawlings R, et al.: Seasonal birth patterns of neurological disorders. Neuroepidemiology 19:177-185, 2000. doi:10.1159/000026253

3. Kristoffersen S, Hartveit F: Is a woman's date of birth related to her risk of developing breast cancer? Oncology Reports 7:245-247, 2000

4. Prener A, Carstensen B: Month of birth and testicular cancer risk in Denmark. American Journal of Epidemiology 131:15-19, 1990

5. Sorensen HT, Pedersen L, Norgard B, et al.: Does month of birth affect risk of Crohn's disease in childhood and adolescence? BMJ 323:907, 2001. doi:10.1136/bmj.323.7318.907

6. Lawlor DA, Davey Smith G, Mitchell R, et al.: Temperature at birth, coronary heart disease, and insulin resistance: Cross sectional analyses of the British women's heart and health study. Heart 90:381-388, 2004. doi:10.1136/hrt.2002.009548

7. Sorensen HT, Pedersen L, Olsen J, et al.: Seasonal variation in month of birth and diagnosis of early childhood acute lymphoblastic leukemia. JAMA 285:168-169, 2001. doi:10.1001/jama.285.2.168

8. Fossey E, Shapiro CM: Seasonality in psychiatry a review. Canadian Journal of Psychiatry 37:299-308, 1992.

9. Castrogiovanni P, Iapichino S, Pacchierotti C, et al.: Season of birth in psychiatry. A review. Neuropsychobiology 37:175-181, 1998. doi:10.1159/000026499

10. Pjrek E, Winkler D, Heiden A, et al.: Seasonality of birth in seasonal affective disorder. The Journal of Clinical Psychiatry 65:1389-1393, 2004

11. Newman SC, Bland RC: Month of birth and schizophrenia in Alberta. Canadian Journal of Psychiatry 33:705-706, 1988

12. Doblhammer G, Vaupel JW: Lifespan depends on month of birth. Proceedings of the National Academy of Sciences of the United States of America 98:2934-2939, 2001. doi:10.1073/pnas.041431898

13. Salib E, Cortina-Borja M: Effect of month of birth on the risk of suicide. The British Journal of Psychiatry 188:416-422, 2006. doi:10.1192/bjp.bp.105.009118

14. Joiner TE, Pfaff JJ, Acres JG, et al.: Birth month and suicidal and depressive symptoms in Australians born in the Southern vs. the Northern hemisphere. Psychiatry Research 112:89-92, 2002. doi: 10.1016/S0165-1781(02)00183-X

15. Nordstrom P, Samuelsson M, Asberg M, et al.: CSF 5-HIAA predicts suicide risk after attempted suicide. Suicide \& Life-Threatening Behavior 24:1-9, 1994

16. Chotai J, Adolfsson R: Converging evidence suggests that monoamine neurotransmitter turnover in human adults is associated with their season of birth. European Archives of Psychiatry and Clinical Neuroscience 252:130-134, 2002. doi:10.1007/s00406-002-0372-7

17. Beck AT, Lester D. Attempted suicide and month of birth. Psychological Reports 33:506, 1973

18. Rock D, Greenberg D, Hallmayer J: Season-of-birth as a risk factor for the seasonality of suicidal behaviour. European Archives of Psychiatry and Clinical Neuroscience 256:98-105, 2006. doi: 10.1007/s00406-005-0614-6

19. Riala K, Hakko H, Räsänen P: Birth during autumn is a risk for adolescent self-mutilative behavior. Neuropsychobiology 56:14-18, 2007. doi:10.1159/000109972

20. Bondy B, Buettner A, Zill P: Genetics of suicide. Molecular Psychiatry 11:336-351, 2006. doi: 10.1038/sj.mp.4001803

21. Dumais A, Lesage AD, Lalovic A, et al.: Is violent method of suicide a behavioral marker of lifetime aggression ? The American Journal of Psychiatry 162:1375-1378, 2005. doi:10.1176/appi.ajp.162.7. 1375

22. Cailhol L, Allen M, Moncany AH, Cicotti A, Virgillito S, Barbe RP, Lazignac C, Damsa C: Violent behavior of patients admitted in emergency following drug suicidal attempt: A specific staff educational crisis intervention. General Hospital Psychiatry 29:42-44, 2007. doi:10.1016/j.genhosppsych.2006. 10.007 
23. Roggenbach J, Muller-Oerlinghausen B, Franke L: Suicidality, impulsivity and aggression-is there a link to 5HIAA concentration in the cerebrospinal fluid? Psychiatry Research 113:193-206, 2002. doi: $10.1016 / \mathrm{S} 0165-1781(02) 00230-5$

\section{Author Biographies}

Lionel Cailhol, M.D. graduated as an adult psychiatrist in Toulouse University in 2005. During his formation he specialized 1 year in clinical research in Geneva University Hospital and 1 year at the Clinical Investigation Center (INSERM/Toulouse University Hospital). His clinical research interest is in suicidal behavior for patient presenting borderline personality disorders. He is currently psychiatrist in Montauban General Hospital and in the Toulouse Clinical Investigation Center.

Raluca Moraru, M.D. studied medicine in Iasi in Romania. She is doing her training in adult psychiatry in Brussels. In 2007, she realized a clinical research training period in Geneva University Hospital in the emergency psychiatry department with Cristian Damsa. Her work focused on suicidal behavior in patients admitted in emergency unit.

Remy Barbe, M.D. studied medicine in Grenoble University. Then he specialized in child and adolescent psychiatry in Lyon, Geneva and Pittsburgh University where he is still adjunct professor. He studies depression and suicidal behavior in child and adolescent. He is head of the inpatient units and adolescent research in the child and adolescent psychiatry division of Geneva University Hospital.

Anne Hélène Moncany, M.D. is doing her training in adult psychiatry in Toulouse University Hospital. Since 2006 she works in clinical research with Lionel Cailhol and Cristian Damsa about suicidal behavior for patients admitted in emergency psychiatry room.

Sophie Garcin, M.D. is a medical student in Geneva University Hospital. Her interest in clinical research motivates her to involve in different studies during her training psychiatric period. She actively participates in the presenting work. She plans to specialize in adult psychiatry and clinical research.

Coralie Lazignac, M.D. studied medicine in Grenoble University and she specialized in adult psychiatry in Nancy, Lyon and Geneva University Hospital. Her clinical research interest focuses on therapeutic alliance and suicidal behavior for patients presenting crisis life situations. She is psychiatrist in the emergency psychiatry department of Geneva University Hospital.

Cristian Damsa, M.D. studied medicine in Brussels. He specialized in adult psychiatry in Brussels, Luxembourg, Strasbourg, and Geneva. Following his work in Colorado University, where he is adjunct professor, he obtained his Privat Docent in 2008 in Geneva, Switzerland. His clinical research focuses on quality of care, crisis intervention, psychotherapy, and dissociative disorders. He is also the head of ISRA, in private practice. 